\title{
Importance of holistic life education amid technology paradox
}

Edara, Inna Reddy $\bowtie$

Graduate Institute of Educational Leadership \& Development,

Fu Jen Catholic University, Taiwan (065049@mail.fiu.edu.tw)

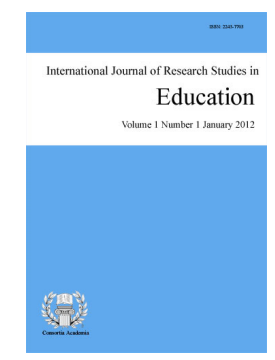

ISSN: 2243-7703 Online ISSN: 2243-7711

OPEN ACCESS

\section{Abstract}

Technologies have been deeply influencing the lifestyle of the people in the modern world. They, on the one hand, allure people to get involved with all the new gadgets, yet, on the other hand, force them to focus on what is important and appropriate for their lives. In this sense, technology is a paradox, for it offers humans great possibilities and at the same time, it confines them in what they do and how they do it. For instance, new technologies in the form of websites and online channels enable people to access enormous loads of information. However, due to the lack of constraints on what sort of information and content is made available online, people constantly need to rely on their judgment to select what's relevant. This selection requires a certain degree of media literacy and self-discipline. Thus, given the reality of the paradox of technology, the liberal course in holistic life education gains an added significance. Holistic education is said to encompass a wide range of philosophical orientations and pedagogical practices, with a special emphasis on wholeness and integration. For many decades, Fu Jen Catholic University in Taiwan has been offering a core course on Philosophy of Life in training and graduating students with a holistic perspective on life. Yet, discerning the technological development and educational needs and mindsets of the current generation of students, Fu Jen has been trying to respond to the signs of the times by appropriately changing the holistic education curricula and methods of instruction to attain the goals of value-based education for life amid technology paradox. Therefore, this paper tried to elucidate the continued importance of holistic life education in the context of the paradox of technology with a special focus on the Philosophy of Life course at Fu Jen Catholic University.

Keywords: technology paradox; holistic education; philosophy of life; Fu Jen University 


\section{Importance of holistic life education amid technology paradox}

\section{Introduction}

It is an undeniable fact that modern lifestyle, economy, educational system, social interactions, and personal development have changed dramatically with ever-advancing, more ingenious, and easily accessible technologies. Such technological progress allures people to get involved with all the new gadgets, yet forces them to be selective and to focus on what is important and appropriate for their lives. If people are not able to filter the use of technologies, they get distracted, confused, and eventually lead a life that is less efficient and less meaningful. In this sense, technology is a paradox, for it offers humans great possibilities and at the same time, it confines them in what they do and how they do it. For instance, new technologies in the form of websites and online channels enable us to access enormous loads of information. However, due to a lack of constraints on what sort of information and content is made available online, people constantly need to rely on their judgment to select what's relevant. This selection requires a certain degree of media literacy and self-discipline.

People also get lazy and live sedentary lives by using various gadgets, which in turn curtails the potential use of their brains. There is also a danger of becoming dependent on and even getting addicted to gadgets. In other words, with the use of boundless and easy communication through social media, people tend to forget how great and valuable are interpersonal relations. Besides, when communication is processed through different mediated channels, the messages will never be as rich and clear as those that occur in face to face interactions, which further lead to misunderstandings and interpersonal conflicts. Besides, being connected online with everyone, in any place and at any time makes it difficult to live in the here and now, and leads to losing contact with oneself and the people we care about. When people spend so much time in virtual worlds, they may lose touch with the real world.

Thus, given the reality of the paradox of technology, the liberal course in holistic life education gains an added significance. Holistic education, which began as a movement in response to the dominant "mechanistic" worldview of mainstream education, is said to encompass a wide range of philosophical orientations and pedagogical practices, with a special emphasis on wholeness and integration. As an eclectic and inclusive movement, it attempts to avoid excluding any significant aspects of the human experience and foster more dynamic and holistic views of reality. Holistic education also proposes that educational experiences promote a more balanced development of the intellectual, physical, religious, and spiritual, affective and emotional, relational and social, and aesthetic and ecological aspects of an individual.

Fu Jen Catholic University, with her Catholic spirit and universal mission, promotes the realization of holistic education in the Taiwanese cultural context by offering various core courses, including Philosophy of Life, which has been considered the flagship course of Fu Jen Catholic University, and has been implemented successfully for many decades in forming and graduating students with a holistic perspective. Yet, discerning the technological development, and the signs of the educational needs and mindsets of the current generation of students, Fu Jen has been trying to heed the call of the paradigm shift in safeguarding its core Catholic spirit and founding mission by appropriately changing the holistic education curricula and methods of instruction to attain the goals of value-based education for life amid technology paradox.

Therefore, in this paper, elucidating the context of the paradox of technology and emphasizing the need for holistic life education, I would like to present some thoughts on the current status of the course on Philosophy of Life at Fu Jen Catholic University. While doing so, I hope to present and clarify the role of technology in formal education in general and in holistic life education in particular, with a special analysis of the Philosophy of Life course at Fu Jen Catholic University in Taiwan. 


\section{Technology and education}

The advancement of technology seems to have an impact on all aspects of people's lives. But, has technology impacted education? Has technology changed how the educators instruct and how the pupils learn? A look at the $14^{\text {th }}$ century depiction by Laurentius de Voltilina (Wikimedia, 2020) of a university lecture in medieval Italy may seem to depict that modern education remains much the same as it has been for many centuries.

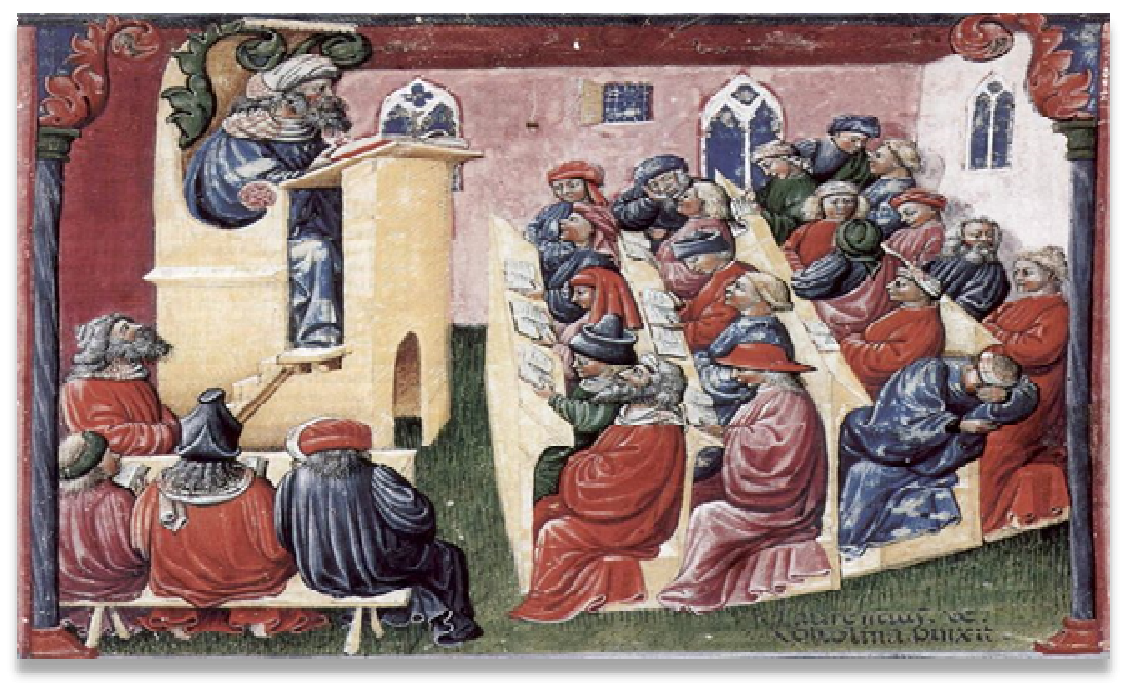

Depiction 1: Henricus de Alemannia con i suoi studenti (Henricus de Alemannia with his students).

The Depiction 1 illustrates that the lecturer is instructing from a podium at the front of the classroom while the students sit in rows. Some of the students appear to be following the lecture with open books in front of them, whereas a few are looking bored, some others are chatting with their neighbors, and one even appears to be sleeping. Modern-day classrooms do not look much different, except that the students look at their gadgets instead of books, eat, chat, and even sleep comfortably. Hence, a cynic would say that all the advances in technology have done practically nothing to impact education (Purdue, 2020). However, on the other hand, as the observations and practicalities of the modern-day classrooms indicate, technology has impacted and continues to impact the understanding of education, and the imparting and acquisition of knowledge.

\section{Impact of modern technology on education}

Technology has changed the way we live our lives by deeply impacting different facets of life. Several complex and critical processes are being carried out with ease and greater efficiency with the help of modern technology (Raja \& Nagasubramani, 2018). Technology continues to introduce profound changes in the everyday life of people. There is a rush to embrace every new gadget as soon as it comes into the market. Both individuals and institutions are being encouraged to advance the development of technology, consume them, and learn to fit into the thought processes and behavioral patterns dictated by the interlocking systems of technology (Bowers, 1998), thus making them either just believe or truly become competent in using many technologies (Feenberg, 2010).

Technology has also revolutionized the field of education (Hechter, Phyfe, \& Vermette, 2012; Raja \& Nagasubramani, 2018). In fact, with the onset of using modern and ever-advancing technology in education, it has become easier and more efficient for teachers to impart knowledge and for students to acquire it. Undoubtedly, the use of technology has made the process of teaching and learning all the more efficient, practical, and even enjoyable. Research has shown that the use of modern technology elevated the interactivity 
and learning process of students. In the field of education, technology has the following benefits: internet connection and round the clock availability; feasibility of online training, and the efficient use of projectors and visuals (Raja \& Nagasubramani, 2018).

Studies have reported that the use of technology has a vast impact on education in terms of both acquisition and absorption of knowledge to both instructors and learners (see Hechter, et al., 2012; Raja \& Nagasubramani, 2018). For learners, the impact occurs through the promotion of active and collaborative learning, creative and integrative learning, and evaluative learning. For instructors, technological developments enhance teaching resources and tools beyond geographical borders. On the flip side, the use of technology has its disadvantages as well, such as poor writing skills, increasing plagiarism and incidents of cheating, lack of focus, and underdeveloped cognitive and analytical skills. From the institutional and instructor point of view, the use of technology in education is time-consuming and costly, instructors are required to continuously update their knowledge and use of technological tools, and both the instructors and learners in some geographical areas can't afford modern technologies.

In other words, the trend in technological advancement and its widespread consumerism seems to turn skills, relationships, and knowledge into commodities. Further, the use of technology appears to commodify even more aspects of individual and community life. All technologies amplify certain aspects of individual experience and cultural values while reducing some other aspects and even losing them entirely form awareness. For example, computers tend to amplify forms of context-free knowledge but overlook contextualized experiences. Technologies tend to amplify a conduit view of language but fail to recognize the metaphorical nature of language. Gadgets tend to amplify the view that individuals are autonomous decision-makers while obfuscating the importance of relationships in creating shared knowledge (Bowers, 1998). People tend to see technologies as almost natural to living, but they are determined by the meanings people give them (Feenberg, 2010).

Further, educational institutions are indoctrinating the students into believing that technology-mediated learning and communication represent a superior and empowered form of education. Educational institutions also fail to help their students recognize that objective data of information represent another person's specific way of knowing and interpreting (Bowers, 1998). Thus, given both the advantages and disadvantages of the role of technology in education, it is not a surprise to say that technology, particularly in the field of education, is a paradox.

\section{The paradox of technology}

A paradox is said to maintain that something is both $X$ and not- $X$ at the same time, in which, a pure and fixed equilibrium between opposites cannot be achieved. In the world of technology, two different perspectives exist and vary on several dimensions. One perspective sees technology as elemental to modern life and argues that technology provides freedom, control, and efficiency in time and effort. The other perspective argues that technology degrades the environment, decreases human competence, and encourages human dependence and passivity (Mick \& Fournier, 1998). Along this spectrum of two opposite perspectives, many scholars have tried to discuss and delineate the dimensions of the paradoxes of technology (see Table 1).

Feenberg (2010, p. 13) said the paradox of the parts and the whole explains that the origin of the complex whole lies in the parts but in reality, the parts find their origin in the whole to which they belong. The paradox of the obvious and the hidden says that what is most obvious is most hidden. The paradox of the origin and the present suggests that there is a presence of the past in the present. The paradox of efficiency and success indicates that efficiency does not explain success, rather success explains efficiency. The paradox of action and reaction explains that in acting we become the object of the action. The paradox of the means and the end indicates that the means are the end. The paradox of complexity and simplicity suggests that simplification complicates. The paradox of value and fact indicates that values are subjective desires with no basis in reality. The paradox of democracy and tyranny is that the public is constituted by the technologies that bind it together

4 Consortia Academia Publishing (A partner of Network of Professional Researchers and Educators) 
Importance of holistic life education amid technology paradox

but in turn, it transforms the technologies that constitute it. The paradox of conquest and the spoils explains that the things we as a society do to nature are also things we do to ourselves.

\section{Table 1}

List of technology paradoxes

\begin{tabular}{|c|c|}
\hline Reference & Technology Paradoxes \\
\hline Feenberg (2010) & $\begin{array}{l}\text { The paradox of the parts and the whole } \\
\text { The paradox of the obvious and the hidden } \\
\text { The paradox of the origin and the present } \\
\text { The paradox of the efficiency and the success } \\
\text { The paradox of action and reaction } \\
\text { The paradox of the means and the end } \\
\text { The paradox of complexity and simplicity } \\
\text { The paradox of value and fact } \\
\text { The paradox of democracy and tyranny } \\
\text { The paradox of conquest and the spoils }\end{array}$ \\
\hline Bowers (1998) & $\begin{array}{l}\text { Cultural diversity and cultural unity } \\
\text { Western and non-Western approach to technology } \\
\text { Development and sustainability } \\
\text { Commodification of technology and knowledge } \\
\text { Market expansion and community viability } \\
\text { Technology and traditions } \\
\text { Technologies and patterns of thinking and values } \\
\text { Technology and the metaphorical language } \\
\text { Technology and social justice }\end{array}$ \\
\hline Larsen (2015) & $\begin{array}{l}\text { Connection and isolation } \\
\text { Unity and fragmentation. } \\
\text { Friends and enemies } \\
\text { The more knowledge there is, the less we know. } \\
\text { Information overload and information deficit } \\
\text { Potential for both good and evil } \\
\text { Power/ control and freedom } \\
\text { Strength and vulnerability } \\
\text { Utility and service } \\
\text { The more time-saving devices we have, the less time we have. } \\
\text { Productivity and consumption }\end{array}$ \\
\hline Mick \& Fournier (1998) & $\begin{array}{l}\text { Control and chaos } \\
\text { Freedom and enslavement } \\
\text { New and obsolete } \\
\text { Competence and incompetence } \\
\text { Efficiency and inefficiency } \\
\text { Fulfills needs and creates needs } \\
\text { Assimilation and isolation } \\
\text { Engaging and disengaging }\end{array}$ \\
\hline
\end{tabular}

Bowers (1998) described the paradox of technology in terms of gains and losses. For example, Browns said that "We are becoming dependent on a technology that we understand in terms of technical applications. But we are unable to recognize the connections between the cultural forms of knowledge that we are losing through the educational use of computers" (p. 50). Bowers further described the paradox of technology by saying that although technology is the dominant force in influencing our cognitive, moral, aesthetic, and relational aspects, it is still imperative to study the cultural non-neutrality of technology. For without a balance, the current trend of turning knowledge, skills, relationships, and leisure into commodities will continue.

Bowers (1998, p. 57) listed a few key points in understanding technology paradox issues. He called for an understanding of the cultural mediating characteristics of technology that threatens cultural diversity and ecological sustainability and researching the characteristics of technologies based on the principles of ecological design. He asked to take into consideration the relationship between different forms of technology and the commodification of knowledge, and evaluate how the expansion of market forces undermine the viability of communities and natural systems. He summoned to assess the impact of different forms of technology on traditions that contribute to the self-sufficiency of community life, and gauze the influence of technologies on patterns of thinking and values. Bowers also requested to understand the impact of technology on the metaphorical language that influences how relationships are established and maintained and engage in reflection on social justice issues that are connected to different forms of technology. 
Bowers (1998) said that in effect, the list of paradoxes forms the foundation for making decisions about technological innovation and progress. Further, the understanding of the gains and losses of technology should lead to a systematic study of the issues at hand and thus avoid equating technological innovation with progress.

In describing the technology paradoxes, Larsen (2015) outlined that the more technology fosters unity, the more it enables fragmentation, and technology breeds frenemies (friends and enemies). He also said that the more knowledge there is, the less we know, and that technology leads to a state of information overload and information deficit simultaneously. Further, however much good technology does, its potential for evil will always be greater. In terms of power and control, the more powerful technology is, the fewer people there are who control it; the more powerful technology is, the fewer power people have to control it; the more powerful technology is, the greater its potential for diminishing the freedom and control of individuals and organizations, and the more technology empowers users, the more potential it has to control freedom. Additionally, the larger technology becomes, the more vulnerable it becomes; the more technology serves us, the more we have to meet its needs; the more time-saving devices we have, the less time we have, and the more technology increases productivity, the fewer people there are who can buy what is produced.

Larsen (2015) said that we are embracing technology for its benefits without understanding its consequences. Without denying the benefits, we need to acknowledge that technology is a relentless and accelerating force unto itself, without whose control, the disruption is inevitable.

Mick and Fournier (1998, p. 126) said that technology can facilitate order and disorder simultaneously. Technology can facilitate independence or fewer restrictions, and it can also lead to dependence or more restrictions. New technologies provide the user with the most recently developed benefits of scientific knowledge, and new technologies are already or soon to be outmoded as they reach the marketplace. Technology can facilitate feelings of intelligence or efficacy, and it can also lead to feelings of ignorance or ineptitude. Technology can facilitate less effort or time spent on certain activities, and it can lead to more effort or time spent on certain activities. Technology can facilitate the fulfillment of needs or desires, and technology can also lead to the development or awareness of needs or desires previously unrealized. Technology can facilitate human togetherness, and it can also lead to human separation. It can facilitate involvement, and it can also lead to disconnection.

The technological paradoxes described by Larsen (2015), Bowers (1998), Feenberg (2010), and Mick and Fournier (1998) have some commonalities and overlapping elements. These can be summarized into some relevant categories and corresponding elements, as shown in Figure 1.

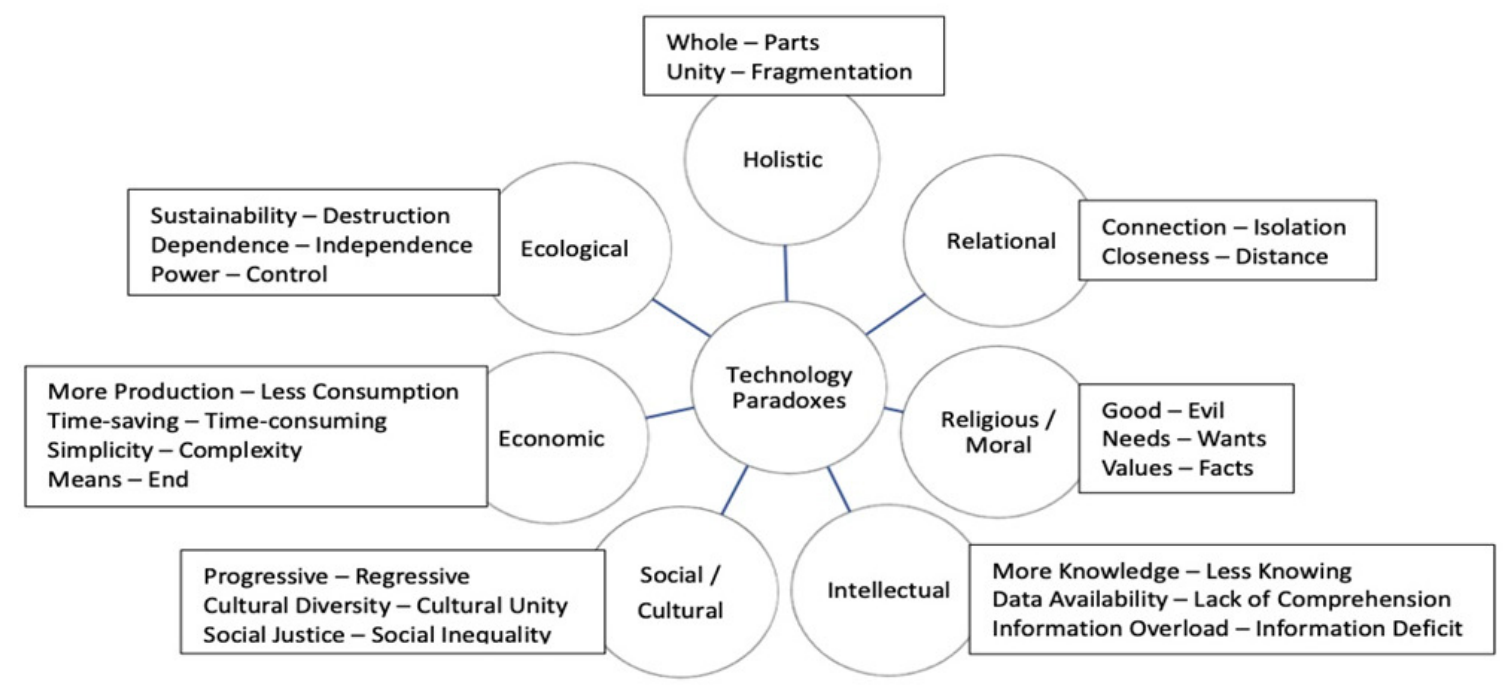

Figure 1. Categories and elements of technology paradoxes. 


\section{Holistic education amidst technology paradox}

Given the prevalent use of technology in education and knowing that the use of technology in itself leads to certain paradoxes, it is all the more important that emphasis is placed on holistic education. The existence of technology paradoxes further proves that the mere use of technology in education is insufficient; rather it should be made sure that technology is present in sufficient quantity, linked to relevant ideas, experienced as socially and personally relevant, and leads to holistic growth.

\subsection{The concept of holistic education}

The concept of "holistic" can be traced back to ancient traditions and indigenous cultures. According to indigenous cultures, everything in life is interdependent and interconnected. Although all living beings may be conceived as independent under certain circumstances and in particular contexts, in reality, they are tied into many overlapping patterns and interlocking subsystems, such as institutions, families, religions, cultures, economies, and ecologies. This innate relational tendency in all organisms, on the one hand, leads them to co-exist in a state of belonging and helps them to thrive in mutually beneficial and supportive relationships, and on the other hand, it helps each organism to achieve its unique identity. These assumptions of relational perspective and symbiotic relationships demand a holistic or global consciousness (Coates, Gray, \& Hetherington, 2006), including in the area of formal higher education.

With the indigenous worldview as the underlying phenomenon, the formal "holistic education" movement took form as a recognizable field of study and practice in the mid-1980s in North America and has been emerging as a response to the dominant "mechanistic" worldview of mainstream education in seeking to challenge the fragmented and reductionist assumptions of mainstream culture and education (Miller, 2004). Holistic education, thus, encompasses a wide range of philosophical orientations and pedagogical practices, with a special emphasis on wholeness. As an eclectic and inclusive movement, it attempts to avoid excluding any significant aspects of the human experience and foster more dynamic and holistic views of reality. Holistic education also proposes that educational experiences promote a more balanced development of and cultivate relationships among different aspects of the individual, such as intellectual, physical, spiritual, affective, emotional, relational and social, aesthetic, and ecological. Thus, holistic education is concerned not just with narrowly defined basic skills and intellectual knowledge systems, but also with life experiences and integration (Mahmoudi, Jafari, Nasrabadi, \& Liaghatdar, 2012).

UNESCO (1996) noted four 'Pillars of Learning' in holistic education in the twenty-first century: (1) Learning to know, which starts with learning to ask. To ask is a natural act of human consciousness in its search for knowledge. Learning to know means empowering the attributes of consciousness to exercise skills, such as paying attention, listening, perceiving, and developing curiosity, intuitiveness, and creativity. Learning to know means having the ability to direct and take responsibility for one's learning, keeping oneself up-to-date, and knowing where to look for knowledge. In this sense, learning to know is a form of scientific awareness. (2) Learning to do, which, in the era of constant change that is upon us, means learning to change the society through intelligence, responsible action, service, and productive work. (3) Learning to live together, which means learning to live responsibly, respecting and cooperating with other people and with all the living organisms on the planet. The fundamental principle of this pillar of learning is interdependence and connectedness, that is, gaining knowledge of the network of life. Thus, learning to live together must help us, on the one hand, to overcome prejudice, dogmatism, discrimination, authoritarianism, and stereotypes, and on the other hand, to develop empathy and cooperative social behavior in caring and sharing, respect for other people and their cultures and value systems, the capability of resolving conflicts through dialogue, and competency in working towards common objectives. (4) Learning to be, which means the discovery of true human nature, and an encounter with the essence of oneself. It is learning to belong to the whole through the discovery of our universal dimension, where genuine human values, not individual human values, reside. It is the discovery of one's being and the inner wisdom achieved through self-knowledge. 
These four pillars lead one to reach the goal of holistic education. Forbes (2003) said that the goal of holistic education is best encapsulated by the term 'ultimacy.' He defined ultimacy as having two meanings: (1) The highest state of being that a person can aspire to. This state can be either a stage of development (e.g., enlightenment); the greatest moment of life that can only be rarely experienced by anyone (e.g., grace), or a phase of life that is uncommon in the population but usually is a rare experience in any particular individual's life (e.g., Maslow's peak-experience). (2) A concern or engagement that is the greatest that a person can aspire to (e.g., being in service to something sacred). Forbes said that these two meanings can overlap or intertwine. Ultimacy is the highest potential of the student who is involved in a holistic educational process. In addition to ultimacy, Miller (2007), for instance, frames the goal of holistic education as transformation, arguing that the core motto of holistic education as transformation is to seek the continuing growth of the individual and society.

\subsection{Holistic education at Fu Jen Catholic University}

Fu Jen Catholic University is an academic community of students, faculty, and staff closely associated with fostering character formation and holistic growth based on Truth, Goodness, Beauty, and Holiness. Thus, holistic education has been the core value of Fu Jen Catholic University since its establishment. The founding spirit of Fu Jen Catholic University states: "Moved by the Christian understanding of love and inspired by the high ideals of Confucian education, it adopted the name "Fu Jen" to give expression to its universal vision and mission realized through holistic education in the Chinese cultural context" (see Christian, 2014; Fu Jen, 2020; Ke, 2015).

Fu Jen was founded in Beijing in 1925 and re-established in Taiwan in 1961 (Ke, 2015). When Fu Jen began its operations in Taiwan, Budenholzer (2013) said that opportunities for higher education in Taiwan were still quite limited and thus Fu Jen emphasized providing quality education in a Catholic atmosphere based on Catholic values. The specific and overt Catholic character of the university was most clearly evident in the presence of the religious, priests, and Catholic laypersons who taught in the academic departments. Many religious and priests were appreciated both for their generous Christian attitude and character as well as for their professional expertise. Additionally, before 1990, each class usually had a small group of Catholic or Christian students, who presumably reinforced the recognition of the Catholic character of Fu Jen by their own Catholic or Christian identity and lifestyle. Hence, during this period, not much thought was given to discuss what it means to be a "Catholic university."

But the current situation of educational institutions in Taiwan is different. Encouraged by the philosophy of neo-liberalism, the number of universities has mushroomed in the recent past (Kuo, 2016). Chou (2014) said there are more than 150 higher educational institutions in Taiwan and the vast majority of Taiwan's 18-22 age cohort studies in a higher educational institution. Under these circumstances of the saturated educational market, Fu Jen finds itself competing with other institutions, while striving to maintain its Catholic character. When the number of priests and religious serving in the university has drastically declined and as the number of Catholic students increasingly becomes almost invisible, the focus of the Catholic character has shifted out of the academic departments and into centralized university-wide units such as the Holistic Education Center, campus ministry and the office for mission and identity (Budenholzer, 2013).

Through Holistic Education Center, Fu Jen's vision and mission of holistic education have been achieved by graduating its students who are characterized by integrated physical, social, intellectual, aesthetic, moral, and spiritual development. Fu Jen also tries to serve the society through various additional academic programs and community services (Holistic Education, 2020; Service Learning, 2020). Overall, for the formation of students, Fu Jen provides a well-balanced division between liberal education and professional training courses with a special emphasis on humanistic discipline, which helps students enrich their lives when they start their careers after graduation (see Fu Jen, 2020; Holistic Education, 2020). One such course that appropriately fulfills the goal of interdisciplinary humanistic growth is Philosophy of Life.

8 Consortia Academia Publishing (A partner of Network of Professional Researchers and Educators) 


\subsection{Philosophy of life}

Philosophy of Life is a vision of the nature or purpose of one's life and of the way that life should be lived. Castellano (2000) identified three specific sources for knowledge acquisition: (1) Traditional knowledge, which is passed on from generation to generation; (2) Empirical or scientific knowledge, which is gained from instruction and learning; and (3) Revealed knowledge, which is acquired through deep reflection and spiritual origins, and usually recognized as a gift. Philosophy of Life is a course that appears to meet these three specific sources of knowledge acquisition, particularly the revealed knowledge.

The core objectives of the Philosophy of Life course at Fu Jen Catholic University (Holistic Education, 2020) include guiding students toward embracing the basic dignity of human life; leading them to self-understanding and openness to life-long learning; providing students with opportunities to reflect upon various aspects of life, such as self-concept, interpersonal and social relations, justice and peace, marriage and family, faith and religion, aesthetics, and ecology; instilling a positive view of life and helping them lead a holistic and integrated life. Figure 2 gives an integrative structure of the Philosophy of Life course.

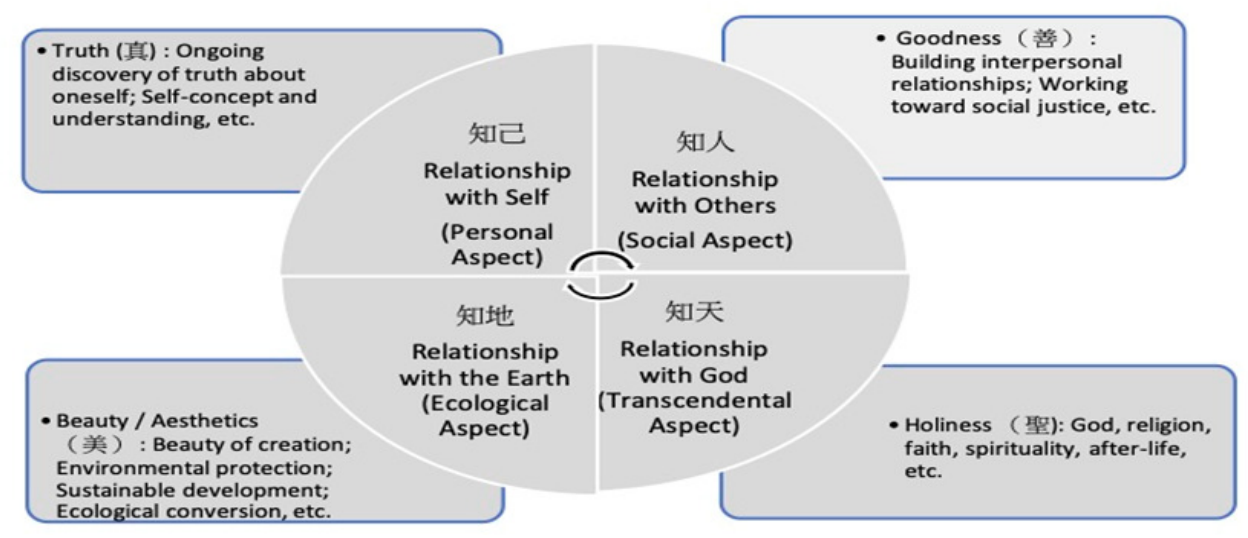

Figure 2. Structure of the course on philosophy of life.

As indicated in the structure (see Figure 2) and goals (see Table 2) of the Philosophy of Life course at Fu Jen Catholic University, it is obvious that it truly is a multifaceted course that gives a chance to students to integrate their academic and campus experiences along the lines of Fu Jen's Catholic spirit and educational mission, while at the same time, it helps students to look forward to a meaningful life post the graduation.

\section{Table 2}

Specific units and objectives of the course on philosophy of life

\begin{tabular}{l|l}
\hline \multicolumn{1}{c|}{ Units } & \multicolumn{1}{c}{ Objectives } \\
\hline 1. Philosophical Thinking & $\begin{array}{l}\text { 1. Understand the essence of philosophy } \\
\text { 2. Know the relation between philosophy and life meaning and values }\end{array}$ \\
\hline 2. Understanding Self & $\begin{array}{l}\text { 1. Define the essence of self } \\
\text { 2. Exploration of self } \\
\text { 3. Self-acceptance }\end{array}$ \\
\hline 3. Interpersonal Relations & $\begin{array}{l}\text { 1. Importance of interpersonal relations } \\
\text { 2. Elements that influence interpersonal relations }\end{array}$ \\
& 3. Establish harmonious interpersonal relations \\
\hline 4. Marriage and Family & $\begin{array}{l}\text { 1. Understand the marriage and family systems } \\
\text { 2. Cultural aspect of marriage and family }\end{array}$ \\
& 3. Influence of family rules and values \\
& 4. Individual's role in one's family of origin \\
\hline 5. Social Care and Justice & 1. Understand human dignity and values \\
& 2. Social engagement and service \\
& 3. Promote and work for social justice \\
\hline 6. Environment and Ecology & 1. Environmental protection and sustainability \\
& 2. Relation between nature and humans \\
& 3. Ecological awareness and conversion \\
\hline
\end{tabular}


Edara, I. R.

Table 2 ...continued

\begin{tabular}{|c|c|}
\hline Units & Objectives \\
\hline 7. Aesthetics & $\begin{array}{l}\text { 1. Understanding aesthetics } \\
\text { 2. Quality of life and integral wellness } \\
\text { 3. Develop aesthetic sense and skills }\end{array}$ \\
\hline 8. Religion and Faith & $\begin{array}{l}\text { 1. Explore world religions } \\
\text { 2. Understand the meaning and significance of religious faith to life } \\
\text { 3. Reflect on religious and spiritual experiences }\end{array}$ \\
\hline 9. Suffering, Illness, Death & $\begin{array}{l}\text { 1. Understand the meaning of suffering } \\
\text { 2. Finitude of life } \\
\text { 3. Make sense of death and after-life issues }\end{array}$ \\
\hline 10. Holistic Life & $\begin{array}{l}\text { 1. Build and live a holistic life that includes Truth, Goodness, Beauty, and Holiness } \\
\text { 2. Chart philosophy of one's own life }\end{array}$ \\
\hline
\end{tabular}

Every person has his or her philosophy of life, and one's philosophy of life may or may not remain constant throughout life, thus making it a developmental and process-oriented journey. If a person intentionally and continuously engages in a process of thinking about and reflecting on his or her life experiences along the developmental stages in discovering life's purpose and meaning, he or she is said to be philosophizing on his or her life. Philosophizing is done both formally and informally; the informal way of philosophizing on one's life is through constant and unstructured reflection, whereas the formal way may include structured forms such as through guidance and mentoring, retreats, reading books, and educational courses. This process is illustrated in Figure 3.

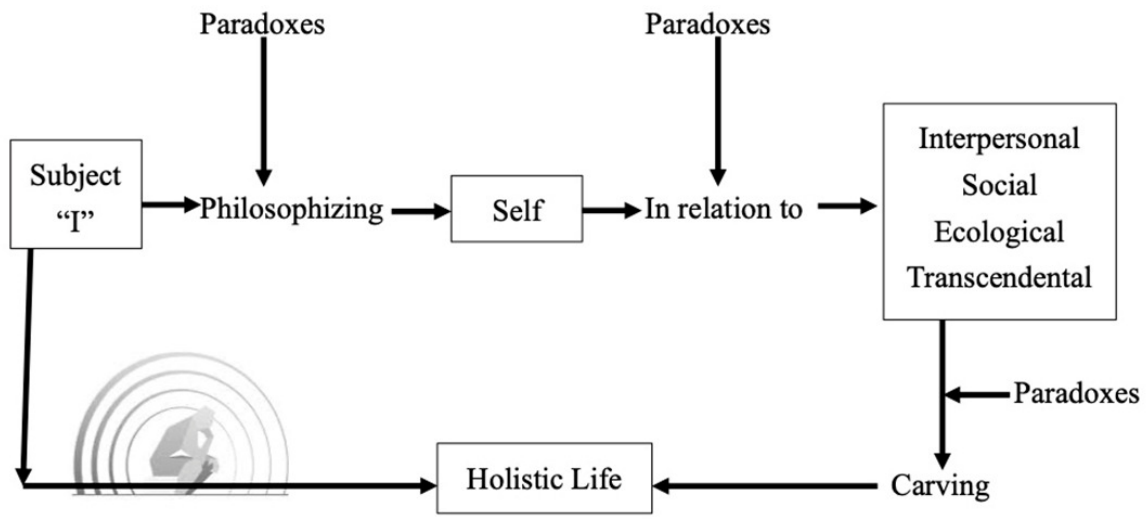

Figure 3. Process of philosophizing life

As shown in Figure 3, the subject (i.e. "I") engages in a philosophical reflection on the self in relation to interpersonal, social, ecological, and transcendental aspects, which together form a holistic life of the subject engaged in this philosophizing process. The Philosophy of Life course at Fu Jen endorses this process in helping students to systematically experience, reflect, analyze, and create an integrated life that solely belongs to them and that is to be lived in relation to others, the environment/nature, and God (transcendent).

In this process of philosophizing, the subject has to deal with various relevant paradoxes at any respective stage. For example, when reflecting on self as a unique individual, it is imperative to deal with the holistic paradox of wholeness and fragmentation, engaging in the creation of body, mind, and soul integration. This initial process naturally leads to the exploration of the self in relation to the other aspects of life, such as interpersonal, sociocultural, ecological, and religious and spiritual. Technology is a useful tool in this process, particularly the explorative and the intellectual aspects of technological tools.

In each specific exploration process, the subject has to deal with various respective paradoxes that are relative to the area of exploration. For instance, while exploring the relationship with others, the subject has to deal with the relational paradoxes of connection and isolation or closeness and distance. How technology as a tool helps an individual to get connected with others and the world is a question to be answered during this process of dealing with relational paradoxes of technology. 
Concerning the social and cultural paradoxes of technology, the subject in the philosophizing process, needs to tackle the paradoxes of social progression and regression, the importance of unity and respect for diversity, acknowledging inequality, and promoting social justice. In the category of ecological paradoxes, the subject is lead to reflect on the intrinsic goodness and value of nature and environment, human's relation to nature, the issue of coexistence, and working toward achieving sustainable developmental goals. Dealing with the ecological paradoxes simultaneously brings one to deal with the economic paradoxes, most specifically with the paradox of means and ends.

The paradox of means and ends is also one of the moral questions that require the subject to reflect on the values, in both relative and absolute terms. Further, morality and ethics are usually never separated from religion and spirituality, which generally deal with the existential and transcendental issues. While living in the ever-advancing technological world and using various technological gadgets, one is inclined to look inward and ask the questions of the meaning of life, the purpose of existence, and life after death, which in turn, leads the subject to philosophize on self. This circular process goes on as the subject continues to live in this technological world that is full of paradoxes, under which circumstances, holistic life education becomes a necessary part of modern education.

\section{Conclusion}

Ongoing technological progress continues to allure every segment of the modern world that people from all spheres get engaged with various types of gadgets, both enhancing and disturbing their lives. For instance, new technologies provide us with easy access to loads of useful information, yet constrain us from developing analytical and reflective skills, thus requiring the users of technology to develop a certain degree of technology literacy. Or, people use technology to communicate, but when misused, the messages lead to misunderstandings and interpersonal conflicts, thus requiring the users to have some sort of self-discipline. Further, when people spend so much time in the virtual world, there is a danger to lose touch with reality. This is the paradox of technology, which consists of at the same time dealing with the whole and the parts, complexity and simplicity, diversity and unity, good and evil, control and freedom, needs and wants, connection and isolation, means and ends, so on.

Thus, given this reality of the paradoxes of technology, the liberal course in holistic life education becomes paramount in training and guiding people to avoid excluding any significant aspects of the human experience and foster a more dynamic and holistic view of life. Fu Jen Catholic University in Taiwan, founded on the principles of Catholic humanism and universal mission, has been endorsing the realization of holistic life education through a formal academic course on Philosophy of Life.

Philosophy of Life is a vision of the nature or purpose of one's life in all its dimensions and of the way that such a life should be lived and experienced. The course on Philosophy of Life at Fu Jen Catholic University is designed as a multidimensional and interdisciplinary academic course with creative pedagogy that helps students to reflect on and integrate their academic experience, campus life, career goals, and carve their philosophy of life in tune with their developmental stages and maturity levels. In line with the Fu Jen's educational mission and goals, Philosophy of Life entails the dimensions of self, interpersonal relations, social issues, ecological and environmental concerns, and existential and transcendental themes.

Amid the presence of various technological paradoxes, the course on Philosophy of Life to a great extent deals successfully with the respective paradoxes through a systematic process of philosophizing on life. It facilitates the process of philosophizing by guiding students through their exploration of self in relation to the major dimensions of interpersonal, social, ecological, and transcendental spheres of life. In this process of philosophizing, students are encouraged to deal with various relevant technological paradoxes about the life's specific dimensions and of the life as a whole, thus helping students to mold their philosophy of life amid various technological paradoxes. 


\section{References}

Bowers, C. A. (1998). The paradox of technology: What's gained and lost? The NEA Higher Education Journal, 14(1), 49-57.

Budenholzer, F. (2013). SVD and SSpS at Fu Jen University: Reflections on university education. Paper presented at Asia Pacific Universities Collaboration Forum, Taipei.

Castellano, M. B. (2000). Updating aboriginal traditions of knowledge. In D. George, H. Budd, \& G. R. Dorothy (Eds.), Indigenous knowledges in global contexts: Multiple readings of our world (pp. 21-36). Toronto, ON: University of Toronto Press.

Christian, M. (2014). Passing on: Looking at the pastoral evangelization history and prospects of Fu Jen Catholic University in Taiwan for 40 years from the historical background and development of the times [xīn huǒ xiāng chuán: cóng lì shǐ bèi jǐng hé shí dài fā zhăn kàn fǔ rén dà xué zài tái wān sì shí nián mù líng fú chuán dí lì shǐ jí zhăn wàng]. Unpublished document.

Coates, J., Gray, M., \& Hetheerington, T. (2006). An ecospiritual perspective: Finally, a place for indigenous approaches. The British Journal of Social Work, 36(3), 381-399. https://doi.org/10.1093/bjsw/bcl005

Feenberg, A. (2010). Ten paradoxes of technology. Techne: Research in Philosophy and Technology, 14(1), 3-15. https://doi.org/10.5840/techne20101412

Forbes, S. (2003). Holistic education: An analysis of its ideas in nature. Brandon, VT: Foundation for Educational Renewal.

Fu Jen University. (2020). Founding spirit and mission. http://www.fju.edu.tw/aboutFju.jsp?labelID=1

Hechter, R. P., Phyfe, L. D., \& Vermette, L. A. (2012). Integrating technology in education: Moving the TPCK framework towards practical applications. Educational Research and Perspectives, 39, 136-152.

Holistic Education. (2020). Goals of holistic education. http://www.hec.fju.edu.tw/FJU-eng/index2.htm

Ke, S. M. (2015). The 90-year historical manuscript of Fu Jen Catholic University 1925 2015: Highlighting the history and testimony of the honor [tiān zhŭ jiào fŭ rén dà xué 90 nián lì shǐ găo 1925 2015: zhāng xiăn zhǔ róng dí lì chéng yǔ jiàn zhèng]. Taipei: Fu Jen Catholic University Press.

Kuo, Y. Y. (2016). Taiwan universities: Where to go? Humanities, 5(1), 12. https://doi.org/10.3390/h5010012

Larsen, M. (2015). 16 paradoxes created by technology: Biting off more than we can chew. https://www.thebookdesigner.com/2015/12/16-technology-paradoxes/

Mahmoudi, S., Jafari, E., Nasrabadi, H. A., \& Liaghatdar, M. J. (2012). Holistic education: An approach for $21^{\text {st }}$ century. International Education Studies, 5(2), 178-186. https://doi.org/10.5539/ies.v5n3p178

Mick, D. G., \& Fournier, S. (1998). Paradoxes of technology: Consumer cognizance, emotions, and coping strategies. Journal of Consumer Research, 25, 123-143. https://doi.org/10.1086/209531

Miller, J. P. (Ed.) (2007). The holistic curriculum (2nd ed.). Toronto, ON, Canada: OISE Press.

Miller, R. (2000). Beyond reductionism: The emerging holistic paradigm in education. The Humanistic Psychologist, 28(1-3), 382-393. https://doi.org/10.1080/08873267.2000.9977003

Miller, R. (2004). Educational alternatives: A Map of the territory. Paths of Learning, 20, 20-27.

Philosophy of Life. (2017). Holistic education center. http://www.hec.fju.edu.tw/FJU-eng/index2.htm

Purdue Online. (2020). How has technology changed education? https://online.purdue.edu/blog/education/how-has-technology-changed-education

Raja, R., \& Nagasubramani, P. C. (2018). Impact of modern technology in education. Journal of Applied and Advanced Research, 3(1), 33-35. https://doi.org/10.21839/jaar.2018.v3iS1.165

Service Learning. (2020). Development of service-learning center at Fu Jen. http://slc.fju.edu.tw/aboutFju.jsp?labelID=26

UNESCO (1996). 'The four pillars of education' in learning: The treasure within. Report to UNESCO of the International Commission on Education for the Twenty-First Century, Paris: UNESCO.

Wikimedia (2020). Henricus de Alemannia con i suoi student. https://commons.wikimedia.org/wiki/File:Laurentius_de_Voltolina_001.jpg? 